\title{
Rates and Correlates of HIV Incidence in Namibia's Zambezi Region From 2014 to 2016: Sentinel, Community-Based Cohort Study
}

Andrew D Maher ${ }^{1,2}$, MPH; Tuli Nakanyala ${ }^{3}$, MPH, MSc; Nicholus Mutenda ${ }^{3}$, MSc; Karen M Banda ${ }^{3}$, MPH; Dimitri Prybylski ${ }^{4}$, MPH, PhD; Adam Wolkon ${ }^{4}, \mathrm{MPH}$; Anna Jonas ${ }^{3}$, MPH, MPA; Souleymane Sawadogo ${ }^{4}, \mathrm{MSc}$; Charity Ntema ${ }^{5}$; Melody Regina Chipadze ${ }^{5}$; Grace Sinvula ${ }^{5}$; Annastasia Tizora ${ }^{5}$; Asen Mwandemele ${ }^{1}$; Shaan Chaturvedi ${ }^{1}$, MPH; Afiba Manza-A Agovi ${ }^{1}$, MPH, PhD; Simon Agolory ${ }^{4}$, MD; Ndapewa Hamunime ${ }^{3}$, MD; David W Lowrance ${ }^{4}$, MD, MPH; Willi Mcfarland ${ }^{1}$, MD, PhD; Sadhna V Patel ${ }^{4}$, MPH

\footnotetext{
${ }_{1}^{1}$ Institute for Global Health Sciences, University of California San Francisco, San Francisco, CA, United States

${ }^{2}$ South African Centre for Epidemiological Modelling and Analysis, Stellenbosch University, Stellenbosch, South Africa

${ }^{3}$ Directorate for Special Programs, Ministry of Health and Social Services, Windhoek, Namibia

${ }^{4}$ Division of Global HIV and TB, US Centers for Disease Control and Prevention, Atlanta, GA, United States

${ }^{5}$ Total Control of the Epidemic, Development Aid from People to People, Windhoek, Namibia
}

\section{Corresponding Author:}

Andrew D Maher, MPH

Institute for Global Health Sciences

University of California San Francisco

Mission Hall, 3rd Floor

550 16th Street

San Francisco, CA, 94158

United States

Phone: 12033137847

Email: andrew.maher@ucsf.edu

\section{Abstract}

Background: Direct measures of HIV incidence are needed to assess the population-level impact of prevention programs but are scarcely available in the subnational epidemic hotspots of sub-Saharan Africa. We created a sentinel HIV incidence cohort within a community-based program that provided home-based HIV testing to all residents of Namibia's Zambezi region, where approximately $24 \%$ of the adult population was estimated to be living with HIV.

Objective: The aim of this study was to estimate HIV incidence, detect correlates of HIV acquisition, and assess the feasibility of the sentinel, community-based approach to HIV incidence surveillance in a subnational epidemic hotspot.

Methods: Following the program's initial home-based testing (December 2014-July 2015), we purposefully selected 10 clusters of 60 to 70 households each and invited residents who were HIV negative and aged $\geq 15$ years to participate in the cohort. Consenting participants completed behavioral interviews and a second HIV test approximately 1 year later (March-September 2016). We used Poisson models to calculate HIV incidence rates between baseline and follow-up and multivariable Cox proportional hazard models to assess the correlates of seroconversion.

Results: Among 1742 HIV-negative participants, 1624 (93.23\%) completed follow-up. We observed 26 seroconversions in 1954 person-years (PY) of follow-up, equating to an overall incidence rate of 1.33 per 100 PY (95\% CI 0.91-1.95). Among women, the incidence was 1.55 per 100 PY (95\% CI 1.12-2.17) and significantly higher among those aged 15 to 24 years and residing in rural areas (adjusted hazard ratio [aHR] 4.26, 95\% CI 1.39-13.13; $P=.01$ ), residing in the Ngweze suburb of Katima Mulilo city (aHR 2.34, 95\% CI 1.25-4.40; $P=.01$ ), who had no prior HIV testing in the year before cohort enrollment (aHR 3.38, 95\% CI 1.04-10.95; $P=.05$ ), and who had engaged in transactional sex (aHR 17.64, 95\% CI 2.88-108.14; $P=.02$ ). Among men, HIV incidence was 1.05 per 100 PY (95\% CI 0.54-2.31) and significantly higher among those aged 40 to 44 years (aHR 13.04 , 95\% CI 5.98-28.41; $P<.001)$ and had sought HIV testing outside the study between baseline and follow-up (aHR $8.28,95 \%$ CI 1.39-49.38; $P=.02)$. No seroconversions occurred among persons with HIV-positive partners on antiretroviral treatment. 
Conclusions: Nearly three decades into Namibia's generalized HIV epidemic, these are the first estimates of HIV incidence for its highest prevalence region. By creating a sentinel incidence cohort from the infrastructure of an existing community-based testing program, we were able to characterize current transmission patterns, corroborate known risk factors for HIV acquisition, and provide insight into the efficacy of prevention interventions in a subnational epidemic hotspot. This study demonstrates an efficient and scalable framework for longitudinal HIV incidence surveillance that can be implemented in diverse sentinel sites and populations.

(JMIR Public Health Surveill 2020;6(2):e17107) doi: 10.2196/17107

\section{KEYWORDS}

HIV; incidence; risk factors; sentinel surveillance; longitudinal studies; cohort studies

\section{Introduction}

\section{Background}

Namibia has a generalized epidemic with 237,000 adults (13.3\%) living with HIV [1]. The prevalence varies by geography, ranging from $7.3 \%$ in the Omaheke region to $23.7 \%$ in the Zambezi region [2]. Namibia's epidemic response is robust. The number of people living with HIV (PLHIV) on antiretroviral treatment (ART) increased from 10,200 in 2004 [3] to 166,000 in 2016 [4]. By 2022, Namibia seeks to reduce new HIV infections by $75 \%$ through scaling-up evidence-based interventions such as medical male circumcision, viral suppression through ART for all PLHIV, and pre-exposure prophylaxis (PrEP) in high-burden regions [5].

Namibia, like most countries with generalized epidemics, has limited ability to assess the impact of prevention interventions and monitor HIV incidence over time. The gold standard for measuring HIV incidence is a longitudinal cohort study, which entails enrolling persons uninfected at baseline and following them over time with repeated testing to detect acquisition of infection. Owing to the perceived high cost and logistical complexity, few surveillance cohort studies have been conducted around the world in recent years [6-10]. Alternative approaches to estimate incidence, including mathematical models [11-13] and assays for recent infection [14], are available. However, models depend on assumptions that are difficult to prove, do not establish causality, and are imprecise at subnational levels. Assays for recent infections have multiple sources of variability, which necessitate large sample sizes and correction factors [14].

A pragmatic method for tracking HIV incidence may be found in the sentinel approach to surveillance [15,16], which involves using data from selected clinics, facilities, or programs. The program's clientele, while not necessarily representative of everyone at risk, is held to reflect changes in the epidemic in the surrounding population. Community-based HIV testing programs, now common in many regions of sub-Saharan Africa, may provide a platform for sentinel incidence surveillance $[17,18]$. Home, mobile, workplace, and school-based programs can increase testing in populations, including repeat testing, by removing social and logistical barriers associated with testing at facilities [19-21]. Therefore, the basic infrastructure for longitudinal sentinel incidence surveillance may already be present in certain high-prevalence areas.

\section{Objectives}

We conducted a sentinel HIV incidence cohort study by adding behavioral measurements and repeated testing to an existing community-based program offering home testing in Namibia's Zambezi region. Our objectives were to estimate HIV incidence, detect new or confirm known risk and preventive factors for HIV acquisition, and assess the feasibility of the sentinel approach to HIV incidence surveillance in a subnational epidemic hotspot.

\section{Methods}

\section{Study Setting and Design}

The study was a prospective cohort implemented in households in Namibia's Zambezi region, situated in the northeast bordering Angola, Botswana, Zambia, and Zimbabwe. Zambezi was chosen because it has the highest prevalence of HIV in the country (23.7\%) [2]. Additionally, a community-based program, Total Control of the Epidemic (TCE), initiated HIV testing and case management for residents of all households in the Zambezi region (20,603 people, 2011 Census) in 2014. TCE's home-based program entailed HIV testing and prevention plans focusing on abstinence, being faithful to 1 partner, condom use, medical male circumcision, repeated testing every 6 to 12 months, and referrals to ART with case management for HIV-positive clients.

TCE mapped all households in the Zambezi region and divided them into 60 programmatic fields, each composed of 6 to 7 geographically contiguous clusters of 60 to 70 households. We selected 1 cluster from each of the 10 fields to include in the sentinel incidence cohort. Clusters were purposively selected to include urban or rural areas of varying distance from the regional capital (Katima Mulilo). Adjacent clusters were paired to form 5 study sites. All households in the sites were eligible for the study. Cohort activities were integrated into the routine activities of TCE's program as they worked on these sites. The cohort aimed to enroll and complete a 1-year follow-up of 1500 persons to obtain reasonably precise HIV incidence estimates and sufficient power to identify strong correlates of seroconversion.

\section{Recruitment and Procedures}

TCE staff approached all households in the sites to offer home-based HIV testing to all residents from December 2015 to July 2016. Residents were identified by the head of the household and assigned unique testing codes. GPS coordinates 
were recorded at each household to facilitate household identification. Residents aged $\geq 15$ years who received the TCE program were invited to complete a baseline interview. Clients who tested negative for HIV were invited to participate in the cohort.

Data on exposure to prevention interventions (eg, HIV testing outside the study, ART use in serodiscordant partnerships, and medical male circumcision), HIV-related risk and preventive behaviors (eg, multiple partners and transactional sex), and demographic characteristics (eg, sex, age, and marital status) were obtained in face-to-face interviews.

Rapid HIV testing was done in the participant's household by TCE staff following the national parallel algorithm, including Alere Determine HIV-1/2 (Abbott Diagnostic Division) and Uni-Gold Recombigen HIV-1/2 (Trinity Biotech) with Clearview Complete HIV-1/2 (Inverness Medical) to resolve discrepant results. Results from the rapid testing algorithm were immediately returned to participants with posttest counseling.

TCE staff collected dried blood spot (DBS) specimens from participants by finger prick on Whatman 903 filter paper. DBS were dried and packaged according to the manufacturer's instructions and shipped weekly to the National Institute of Pathology reference laboratory in Windhoek and stored at $-70^{\circ} \mathrm{C}$ to $-80^{\circ} \mathrm{C}$. A fourth-generation enzyme-linked immunosorbent assay (Vironostika Uniform II bioMérieux-Diagnostics) was used on DBS for quality assurance to confirm every 10th HIV-negative and all HIV-positive rapid test results at baseline and follow-up. Quality assurance results were not returned to the participants. Additional quality assurance was performed according to national standards, including proficiency panels for counselors throughout the study.

Cohort participants were recontacted approximately 12 months after enrollment to complete a follow-up interview and HIV test using the same procedures.

\section{Statistical Analysis}

Proportions and 95\% CIs were calculated to describe the characteristics of the cohort. We used baseline interview data for demographic characteristics, prior testing history, partner's HIV status, and male circumcision. We used follow-up interview data for variables that may have changed from baseline to follow-up, including seeking testing for HIV outside of the study, transactional sex, sex with partners residing outside of the study sites, condom use, and multiple sex partners. We used generalized linear models to assess baseline correlates of cohort participation and completion of follow-up.

Rates of HIV incidence were calculated as the number of seroconversions per 100 person-years (PY) of follow-up. PY was calculated as the number of days between baseline and follow-up/365 for participants who did not seroconvert and one-half the number of days between baseline and follow-up/365 for participants who seroconverted, which is a commonly used technique when the exact date of seroconversion is unknown $[7,22,23]$. To account for possible dependence among participants in the selected field sites, we used the field variable to calculate cluster-robust 95\% CI for incidence rates [24], except when a variable's strata contained 1 or no seroconversions. For these cases, the exact 1- or 2-sided Poisson CI was calculated. We used Cox models to assess potential correlates of HIV seroconversion. Since patterns of intergenerational heterosexual transmission resulting in a higher HIV incidence among young women and older men have been observed elsewhere in sub-Saharan Africa, along with different risk factors for HIV infection prevailing for men and women $[1,8,9,25]$, we modeled data among men and women separately. Variables that had zero seroconversions or failed to meet the proportional hazard assumption were excluded. Variables that produced $P$ values <.10 in the bivariate models were included in the initial multivariable models. We used the variance inflation factor with Stata's vif command to assess the potential for multicollinearity of variables [26]. Any variable with a variance inflation factor greater than 10 was excluded from the multivariable model. Variables with $P<.05$ in the final models were considered significant. The risk of seroconversion was expressed as adjusted hazard ratios (aHR). The analysis was performed using Stata version 12.1 (StataCorp).

\section{Ethical Information}

Participants gave verbal informed consent at baseline and again at follow-up. Participants aged 15 to 17 years gave their assent and were required to have consent from a parent or guardian. No monetary or material incentives were provided. The study was approved by the Institutional Review Boards of the Ministry of Health and Social Services in Namibia and the University of California, San Francisco. The study was reviewed in accordance with the Centers for Disease Control and Prevention (CDC) human research protection procedures and determined to be research, although CDC investigators did not interact with human subjects or have access to identifiable data or specimens for research purposes. All procedures were implemented in accordance with the ethical standards of the abovementioned ethics committees and the Helsinki Declaration of 1975, as revised in 2000 .

\section{Results}

\section{Participation and Retention}

The TCE program offered home-based testing to 1004 households across the 5 sites (Figure 1). Among persons aged $\geq 15$ years residing in these households, $72.63 \%$ (3261/4490) received home-based testing, of whom $68.02 \%$ (2218/3261) completed the baseline interview. Among HIV-negative persons who participated in the baseline interview, 93.2\% (1624/1742) completed the follow-up HIV test and interview. The median follow-up time was 433 days (IQR 397-478), which was notably higher than the intended follow-up time of 365 days. There were no significant differences in follow-up time by age, sex, or urban vs rural sites. Women were more likely than men to receive home-based testing, agree to the baseline interview, and be retained for follow-up. 
Figure 1. Flow diagram of household listing, receipt of home-based HIV testing, participation in the cohort study and follow-up measurements among adults age $\geq 15$ years in five community-based sites of the Zambezi region of Namibia, 2014-2016.

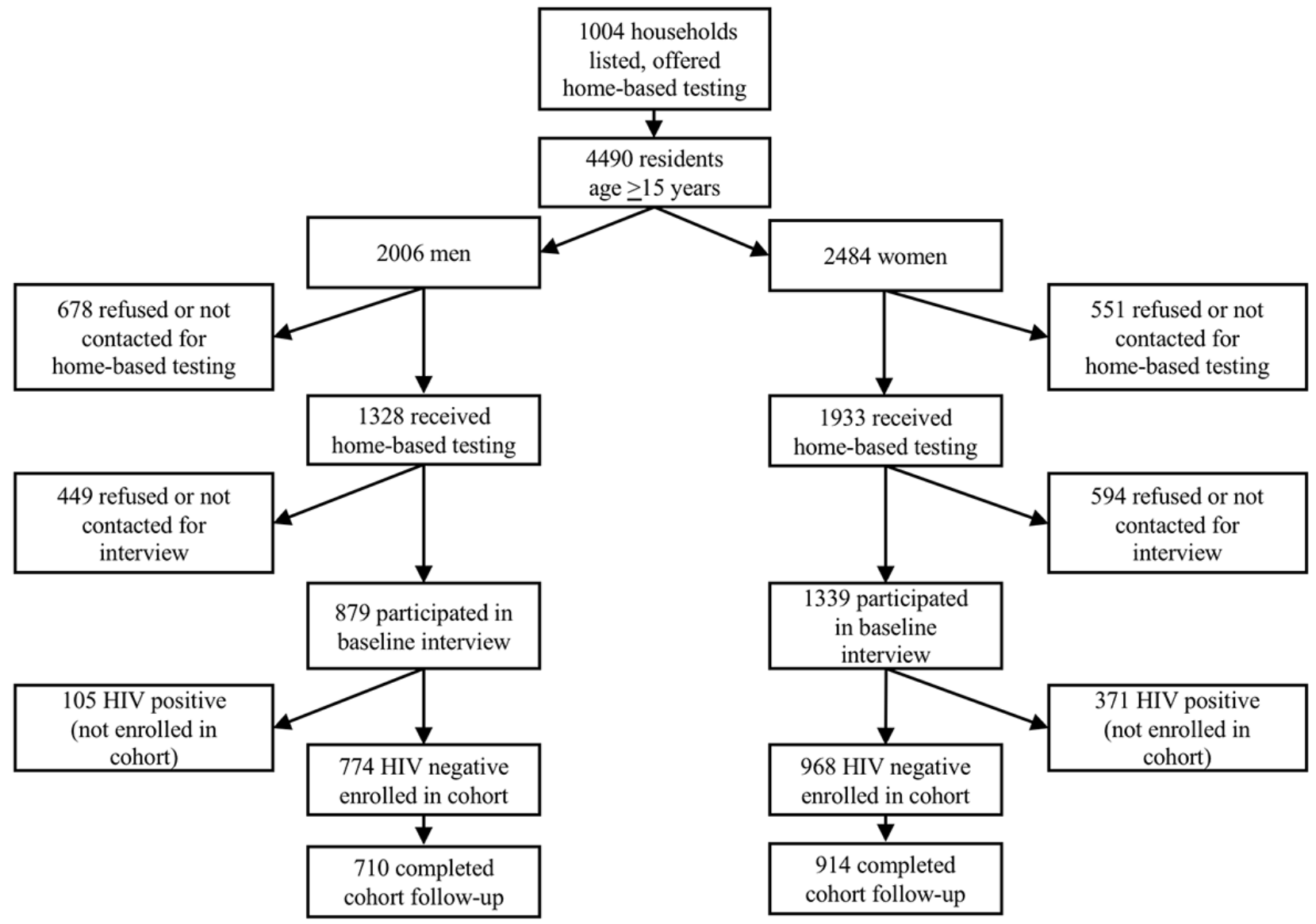

\section{Description of Cohort Participants}

Demographic characteristics and HIV-related risk behaviors of the cohort participants who completed the follow-up are shown in Table 1. Young women aged 15 to 24 years comprised $43.6 \%$ (398/914) of female participants, $25.2 \%$ (230/914) lived in the urban Ngweze site, 65.5\% (599/914) had not tested for HIV in the 12 months before baseline, and $0.9 \%$ (8/914) had engaged in transactional sex in the 12 months before baseline. Key characteristics among men were 5.9\% (42/710) being aged 40 to 44 years, $11.1 \%$ (79/710) seeking HIV testing outside the study in the year before follow-up (ie, in addition to the testing provided by the study), and $4.6 \%$ (32/710) self-reporting circumcision before baseline. Among HIV-negative participants who tested with their partner, 8.6\% (40/463) had an HIV-positive partner, of whom 28\% (11/40) were on ART. Quality assurance through retesting DBS from baseline and follow-up participants detected no misclassification of serostatus. All counselors scored $100 \%$ on the rapid testing proficiency panels during the study. 
Table 1. Demographic and behavioral characteristics of HIV-negative participants who completed baseline and follow-up measurements-household cohort study of adults aged $\geq 15$ years in the Zambezi region of Namibia, 2014 to 2016 ( $N=1624)$.

\begin{tabular}{|c|c|c|c|}
\hline Variable & Total, n (\%) & Women (n=914), n (\%) & Men $(\mathrm{n}=710), \mathrm{n}(\%)$ \\
\hline \multicolumn{4}{|l|}{ Age (years) ${ }^{a}$} \\
\hline $15-19$ & $301(18.53)$ & $176(19.3)$ & $125(17.6)$ \\
\hline $20-24$ & $379(23.34)$ & $222(24.3)$ & $157(22.1)$ \\
\hline $25-29$ & $253(15.58)$ & $134(14.7)$ & $119(16.8)$ \\
\hline $30-34$ & $195(12.01)$ & $107(11.7)$ & $88(12.4)$ \\
\hline $35-39$ & $152(9.36)$ & $69(7.5)$ & $83(11.7)$ \\
\hline $40-44$ & $92(5.67)$ & $50(5.5)$ & $42(5.9)$ \\
\hline $45-49$ & $63(3.88)$ & $30(3.3)$ & $33(4.6)$ \\
\hline $50-64$ & 189 (11.64) & $126(13.8)$ & $63(8.9)$ \\
\hline \multicolumn{4}{|l|}{ Site $^{\mathrm{a}}$} \\
\hline Ngweze urban & $384(23.65)$ & $230(25.2)$ & $154(21.7)$ \\
\hline Mavuluma urban & $356(21.92)$ & $217(23.7)$ & $139(19.6)$ \\
\hline Bukalo rural & $368(22.66)$ & $175(19.1)$ & $193(27.2)$ \\
\hline Ngoma rural & $201(12.38)$ & $101(11.1)$ & $100(14.1)$ \\
\hline Sibbinda rural & $315(19.40)$ & $191(20.9)$ & $124(17.5)$ \\
\hline \multicolumn{4}{|l|}{ Residence $^{\mathrm{a}}$} \\
\hline Rural & $887(54.62)$ & $468(51.2)$ & $419(59.0)$ \\
\hline Urban & 737 (45.38) & $446(48.8)$ & $291(41.0)$ \\
\hline \multicolumn{4}{|l|}{ Age (years) and residence ${ }^{a}$} \\
\hline $15-24$, rural & $328(20.20)$ & $169(18.5)$ & $159(22.4)$ \\
\hline $15-24$, urban & $354(21.80)$ & $229(25.1)$ & $125(17.6)$ \\
\hline$\geq 25$, rural & $559(34.42)$ & $299(32.7)$ & $260(36.6)$ \\
\hline$\geq 25$, urban & $383(23.58)$ & $217(23.7)$ & $166(23.4)$ \\
\hline Currently married $^{\mathrm{a}}$ & 644 (39.66) & $381(41.7)$ & $263(37.0)$ \\
\hline Tested for HIV in the 12 months before enrollment ${ }^{\mathrm{a}}$ & 485 (29.86) & $315(34.5)$ & $170(23.9)$ \\
\hline Tested with a partner at enrollment ${ }^{\mathrm{a}}$ & $463(28.51)$ & $264(28.9)$ & $199(28.0)$ \\
\hline $\begin{array}{l}\text { Had a serodiscordant positive partner (among those tested with a partner at enroll- } \\
\text { ment) }{ }^{\text {a }}\end{array}$ & $40(8.6)$ & $13(4.9)$ & 27 (13.6) \\
\hline $\begin{array}{l}\text { Partner on antiretroviral treatment (among those with serodiscordant positive } \\
\text { testing partner) }\end{array}$ & $11(27.5)$ & $4(30.8)$ & $7(25.9)$ \\
\hline Circumcised (among men only) $^{\mathrm{a}}$ & $\mathrm{N} / \mathrm{A}^{\mathrm{c}}$ & N/A & $32(4.6)$ \\
\hline Sought HIV testing outside the study in past 12 months ${ }^{\mathrm{d}}$ & $212(13.05)$ & $133(14.6)$ & 79 (11.1) \\
\hline Had sex partner residing outside study area in the past 12 months ${ }^{b, d}$ & $144(11.70)$ & $84(12.4)$ & $60(10.8)$ \\
\hline Engaged in transactional sex in the past 12 months ${ }^{\mathrm{d}}$ & $44(2.71)$ & $8(0.9)$ & $36(5.1)$ \\
\hline Used a condom at the last sexual encounter ${ }^{b, d}$ & $677(54.82)$ & $381(56.0)$ & $296(53.3)$ \\
\hline Used condoms consistently with all sex partners in past the 12 months $\mathrm{b}, \mathrm{d}$ & $119(9.64)$ & $58(8.5)$ & $61(11.0)$ \\
\hline Had multiple sex partners in the past 12 months $^{\mathrm{d}}$ & $38(2.34)$ & $12(1.3)$ & $26(3.7)$ \\
\hline
\end{tabular}

${ }^{\mathrm{a}}$ Data collected at baseline.

${ }^{b}$ Among participants who reported having any sex partners between baseline and follow-up ( $\mathrm{n}=1235$, including 680 women and 555 men). 
${ }^{\mathrm{c}}$ N/A: not applicable.

${ }^{\mathrm{d}}$ Data collected at follow-up.

\section{Rates of HIV Incidence}

There were 26 seroconversions in 1954 PY among the 1624 baseline HIV-negative participants who completed the follow-up (Table 2), equating to an overall incidence rate of 1.33 per 100 PY (95\% CI 0.91-1.95). When pooled across age groups, the overall incidence was not significantly higher for women $(1.55$ per $100 \mathrm{PY}, 95 \%$ CI $1.12-2.17 ; P=.26)$ relative to men (1.05 per 100 PY, 95\% CI 0.54-2.31). Among women, most seroconversions occurred in the younger age groups, with 10 out of 17 among women aged 15 to 24 years and 5 among those aged 15 to 19 years (2.42 per $100 \mathrm{PY}, 95 \%$ CI $0.97-7.34$ ). Among men, the incidence was highest among those aged 40 to 44 years (8.21 per 100 PY, 95\% CI 3.76-21.14). When participants were grouped into 8 demographic categories by sex, age (15-24 vs 25 and above), and residence (urban vs rural; Table 2 and Figure 2), the highest incidence was among rural adolescent girls and young women (AGYW) aged 15 to 24 years (3.59 per 100 PY, 95\% CI 1.60-8.69). Rural, older men (>25 years) had the second highest incidence (1.93 per $100 \mathrm{PY}, 95 \%$ CI 0.94-5.01). No seroconversions occurred among men who self-reported being circumcised at baseline ( 0 per $100 \mathrm{PY}, 97.5 \%$ CI 0-9.78). No seroconversions occurred among women ( 0 per $100 \mathrm{PY}, 97.5 \%$ CI $0-80.02)$ or men (0 per $100 \mathrm{PY}, 97.5 \%$ CI 0-45.26) who had an HIV-positive partner on ART. 
Table 2. HIV incidence per 100 person-years by sex and demographic and behavioral characteristics—-household cohort study of adults aged $\geq 15$ years in the Zambezi region of Namibia, 2014 to 2016 ( $\mathrm{N}=1624)$.

\begin{tabular}{|c|c|c|c|c|c|c|}
\hline \multirow[t]{2}{*}{ Variable } & \multicolumn{3}{|l|}{ Women } & \multicolumn{3}{|l|}{ Men } \\
\hline & $\begin{array}{l}\text { Incident } \\
\text { infections }\end{array}$ & $\begin{array}{l}\text { Rate per } 100 \text { person, } \\
\text { years }(\mathrm{CI})^{\mathrm{a}}\end{array}$ & $P$ value & $\begin{array}{l}\text { Incident } \\
\text { infections }\end{array}$ & $\begin{array}{l}\text { Rate per } 100 \text { person, } \\
\text { years }(\mathrm{CI})\end{array}$ & $P$ value \\
\hline Overall & 17 & $1.55(1.12-2.17)$ & .29 & 9 & $1.05(0.54-2.31)$ & $\operatorname{Ref}^{b}$ \\
\hline
\end{tabular}

Age (years) ${ }^{c}$

$15-19$
$20-24$
$25-29$
$30-34$
$35-39$
$40-44$
$45-49$
$50-64$

$\begin{array}{llllll}5 & 2.42(0.97-7.34) & .42 & 0 & 0.00(0.00-2.44) & -^{\mathrm{d}} \\ 5 & 1.88(1.05-3.57) & .68 & 1 & 0.53(0.01-2.93) & \operatorname{Ref} \\ 2 & 1.23(0.31-8.52) & \text { Ref } & 1 & 0.69(0.02-3.87) & .80 \\ 4 & 3.09(1.68-6.61) & .40 & 2 & 1.86(0.50-12.51) & .25 \\ 0 & 0.00(0.00-4.53) & - & 1 & 1.00(0.03-5.57) & .60 \\ 0 & 0.00(0.00-6.25) & - & 4 & 8.21(3.76-21.14) & <.001 \\ 1 & 2.89(0.07-16.10) & .61 & 0 & 0.00(0.00-9.23) & - \\ 0 & 0.00(0.00-2.34) & - & 0 & 0.00(0.00-4.95) & -\end{array}$

Currently married ${ }^{\mathrm{c}}$

$\begin{array}{lllllll}\text { No } & 14 & 2.20(1.38-3.49) & .03 & 6 & 1.12(0.49-2.87) & .79 \\ \text { Yes } & 3 & 0.65(0.25-2.21) & \text { Ref } & 3 & 0.94(0.38-3.08) & \text { Ref }\end{array}$

Site $^{\mathrm{c}}$

Ngweze urban

Mavuluma urban

Bukalo rural

Ngoma rural

Sibbinda rural

Residence $^{\mathrm{c}}$

Rural

Age (years) and residence ${ }^{c}$

$15-24$ and rural
$15-24$ and urban
$\geq 25$ and rural
$\geq 25$ and urban

5
3
3
2
4

$1.88(1.23-3.02)$
$1.17(0.41-3.86)$
$1.47(0.41-5.40)$
$1.59(1.46-1.76)$
$1.81(0.75-5.83)$

$\begin{array}{ll}<.001 & 1 \\ \text { Ref } & 2 \\ .36 & 3 \\ .005 & 2 \\ .11 & 1\end{array}$

$0.58(0.01-3.21)$

Ref $1.29(0.16-4.64) \quad .75$ $1.31(0.27-3.84) \quad .58$ $1.61(1.34-1.96) \quad .34$ $0.70(0.02-3.89) \quad .94$

$\begin{array}{llllll}9 & 1.62(0.99-2.76) & .53 & 6 & 1.20(0.51-3.60) & .54 \\ 8 & 1.47(0.91-2.48) & \text { Ref } & 3 & 0.85(0.23-5.36) & \text { Ref }\end{array}$

ested for HIV in the 12 months before enrollment ${ }^{\mathrm{c}}$

No
Yes

$\begin{array}{llllll}14 & 1.97(1.32-2.95) & .05 & 5 & 0.77(0.32-2.31) & .11 \\ 3 & 0.78(0.33-2.41) & \text { Ref } & 4 & 1.95(1.03-4.24) & \text { Ref }\end{array}$

Tested with a partner at enrollment ${ }^{\mathrm{c}}$

$\begin{array}{lllllll}\text { No } & 16 & 2.05(1.41-2.98) & .05 & 7 & 1.15(0.54-2.75) & .57 \\ \text { Yes } & 1 & 0.30(0.01-1.69) & \text { Ref } & 2 & 0.82(0.22-5.47) & \text { Ref }\end{array}$

Had a serodiscordant positive partner (among those tested with a partner) ${ }^{\mathrm{c}}$

$\begin{array}{lllllll}\text { No } & 0 & 0.00(0.00-1.18) & - & 1 & 0.47(0.01-2.63) & \text { Ref } \\ \text { Yes } & 1 & 6.82(0.17-38.01) & \text { Ref } & 1 & 3.06(0.08-17.03) & .23\end{array}$

Partner on antiretroviral therapy (among those with serodiscordant positive partner) ${ }^{\mathrm{c}}$ 


\begin{tabular}{|c|c|c|c|c|c|c|}
\hline \multirow[t]{2}{*}{ Variable } & \multicolumn{3}{|l|}{ Women } & \multicolumn{3}{|l|}{ Men } \\
\hline & $\begin{array}{l}\text { Incident } \\
\text { infections }\end{array}$ & $\begin{array}{l}\text { Rate per } 100 \text { person, } \\
\text { years }(\mathrm{CI})^{\mathrm{a}}\end{array}$ & $P$ value & $\begin{array}{l}\text { Incident } \\
\text { infections }\end{array}$ & $\begin{array}{l}\text { Rate per } 100 \text { person, } \\
\text { years }(\mathrm{CI})\end{array}$ & $P$ value \\
\hline No & 1 & $9.94(0.25-55.38)$ & Ref & 1 & $4.07(0.10-22.68)$ & Ref \\
\hline Yes & 0 & $0.00(0.00-80.02)$ & - & 0 & $0.00(0.00-45.26)$ & - \\
\hline \multicolumn{7}{|c|}{ Circumcised (among men only) ${ }^{c}$} \\
\hline No & $\mathrm{N} / \mathrm{A}^{\mathrm{e}}$ & N/A & - & 9 & $1.13(0.58-2.49)$ & Ref \\
\hline Yes & N/A & N/A & - & 0 & $0.00(0.00-9.78)$ & - \\
\hline \multicolumn{7}{|c|}{ Sought testing for HIV outside the study in past 12 months ${ }^{f}$} \\
\hline No & 11 & $1.17(0.68-2.12)$ & .14 & 4 & $0.53(0.17-2.42)$ & .03 \\
\hline Yes & 6 & $3.72(1.64-9.27)$ & Ref & 5 & $5.23(1.99-16.65)$ & Ref \\
\hline \multicolumn{7}{|c|}{ Had a sex partner residing outside of study area in past 12 months ${ }^{f}$} \\
\hline No & 13 & $1.82(1.31-2.57)$ & .13 & 4 & $0.67(0.30-1.73)$ & .05 \\
\hline Yes & 3 & $2.98(1.62-6.71)$ & Ref & 2 & $2.79(0.34-10.07)$ & Ref \\
\hline \multicolumn{7}{|c|}{ Engaged in transactional sex in the past 12 months ${ }^{f}$} \\
\hline No & 15 & $1.38(0.88-2.24)$ & .01 & 9 & $1.11(0.55-2.51)$ & Ref \\
\hline Yes & 2 & $22.75(3.79-100)$ & Ref & 0 & $0.00(0.00-8.52)$ & - \\
\hline \multicolumn{7}{|c|}{ Used a condom at the last sexual encounter ${ }^{c}$} \\
\hline No & 9 & $2.52(1.15-5.08)$ & .37 & 1 & $0.32(0.08-1.76)$ & .23 \\
\hline Yes & 7 & $1.53(0.84-3.03)$ & Ref & 5 & $1.41(0.45-7.42)$ & Ref \\
\hline \multicolumn{7}{|c|}{ Used condoms consistently with all sex partners in the past 12 months ${ }^{f}$} \\
\hline No & 14 & $1.88(1.45-2.48)$ & .98 & 7 & $1.21(0.62-2.72)$ & .64 \\
\hline Yes & 2 & $2.82(0.67-20.52)$ & Ref & 1 & $0.87(0.02-4.60)$ & Ref \\
\hline \multicolumn{7}{|c|}{ Had multiple sex partners in the past 12 months ${ }^{f}$} \\
\hline No & 15 & $1.38(0.89-2.25)$ & .02 & 9 & $1.09(0.56-2.41)$ & Ref \\
\hline Yes & 2 & $14.78(3.81-94.41)$ & Ref & 0 & $0.00(0.00-12.07)$ & - \\
\hline
\end{tabular}

${ }^{\mathrm{a}} \mathrm{CIs}$ are cluster-robust unless there are 1 or 0 seroconversions, in which case the CI is Poisson exact. CI is 2-sided $95 \%$ except when there are 0 seroconversions, in which cases $\mathrm{CI}$ is 1 -sided $97.5 \%$.

${ }^{\mathrm{b}}$ Ref is the reference group for Cox models.

${ }^{\mathrm{c}}$ Data collected at baseline.

${ }^{\mathrm{d}} P$ values were not calculated when there were 0 seroconversions.

${ }^{\mathrm{e}} \mathrm{N} / \mathrm{A}$ : not applicable.

${ }^{\mathrm{f}}$ Data collected at follow-up. 
Figure 2. HIV incidence per 100 person-years by age, residence, and sex; household cohort of adults age $\geq 15$ years in the Zambezi region of Namibia, 2014-2016 ( $\mathrm{N=1624).} \mathrm{Error} \mathrm{bars} \mathrm{in} \mathrm{the} \mathrm{figure} \mathrm{represent} \mathrm{two-sided} \mathrm{95 \%} \mathrm{CI,} \mathrm{except} \mathrm{when} \mathrm{there} \mathrm{were} 0$ seroconversions, in which case CI are one-sided and $97.5 \%$.

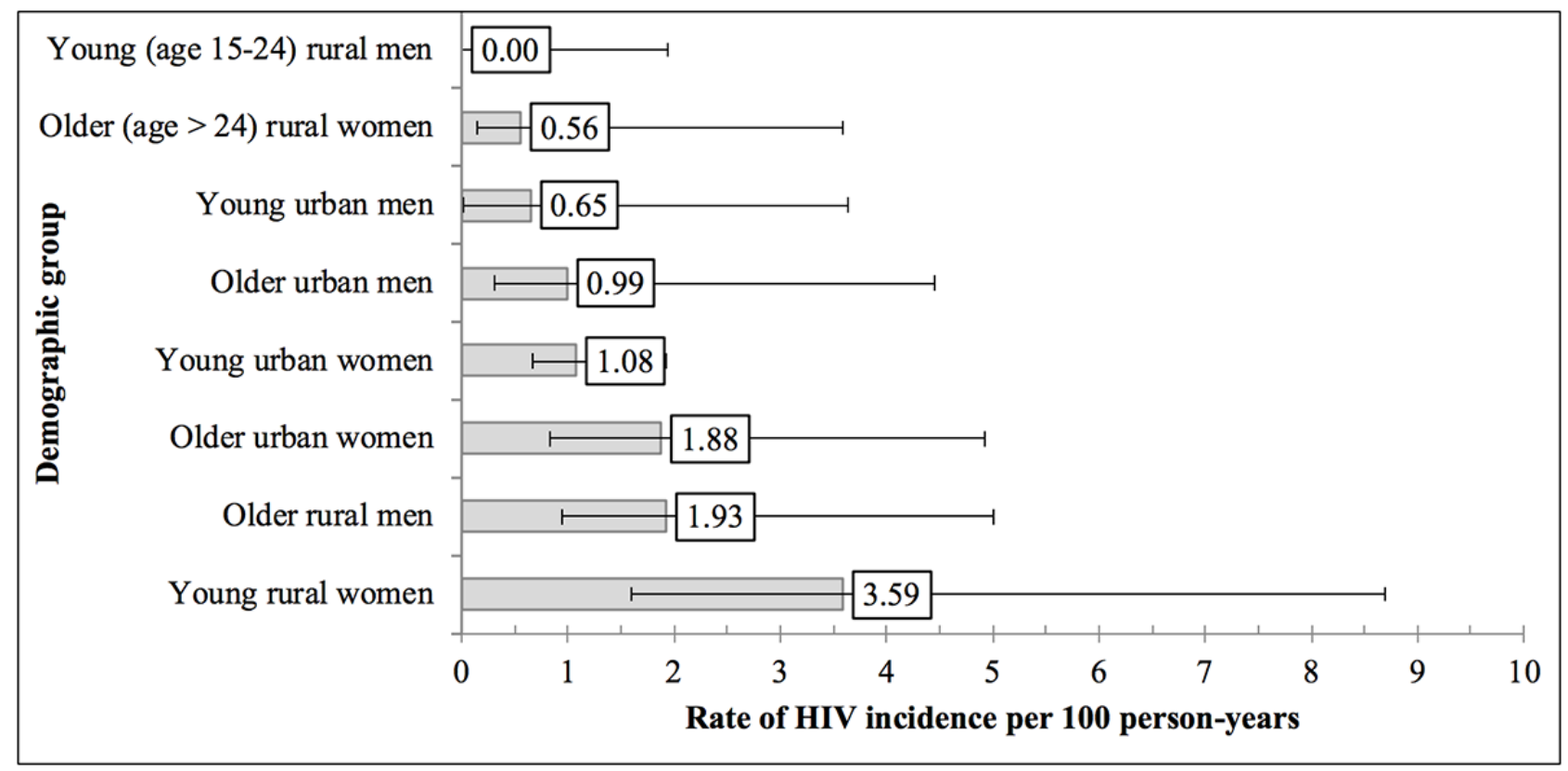

\section{Correlates of HIV Incidence}

In the multivariable model for women (Table 3), factors associated with increased risk for seroconversion were AGYW residing in rural sites vs other women (aHR 4.26, 95\% CI $1.39-13.13 ; P=.01)$, residing in the Ngweze urban site vs other sites (aHR 2.34, 95\% CI 1.25-4.40; $P=.01$ ), not testing for HIV in the 12 months preceding baseline vs testing (aHR 3.38, 95\% CI 1.04-10.95, $P=.05$ ), and engaging in transactional sex vs no transactional sex (aHR 17.64, 95\% CI 2.88-108.14; $P=.02$ ). In the multivariable model for men, the risk of seroconversion was higher among those aged 40 to 44 years relative to other age groups (aHR 13.04, 95\% CI 5.98-28.41; $P<.001$ ). Men who sought HIV testing between baseline and follow-up outside of the study also had a higher risk for seroconversion than men who had not sought testing between baseline and follow-up (aHR 8.28, 95\% CI 1.39-49.38; $P=.02$ ). No multicollinearity among the variables in the models was observed. 
Table 3. Correlates of HIV seroconversion among women and men, multivariable Cox proportional hazards models, and household cohort study of adults aged $\geq 15$ years in the Zambezi region of Namibia, 2014 to $2016(\mathrm{~N}=1624)$.

\begin{tabular}{|c|c|c|c|c|}
\hline Variable & $\begin{array}{l}\text { Full model, adjusted } \\
\text { hazards ratio }(95 \% \mathrm{CI})^{\mathrm{a}}\end{array}$ & $P$ value & $\begin{array}{l}\text { Final model, adjusted } \\
\text { hazards ratio }(95 \% \mathrm{CI})^{\mathrm{a}}\end{array}$ & $P$ value \\
\hline \multicolumn{5}{|l|}{ Women } \\
\hline $\begin{array}{l}15-24 \text { years old and resident of rural site (vs other age and residential } \\
\text { groups) }{ }^{\text {b }}\end{array}$ & $4.17(1.37-12.65)$ & .01 & $4.26(1.39-13.13)$ & .01 \\
\hline Resident of Ngoma rural (vs residents of other sites) ${ }^{b}$ & $0.55(0.05-5.70)$ & .62 & $-^{c}$ & - \\
\hline Resident of Ngweze urban (vs residents of other sites) ${ }^{b}$ & $2.13(1.08-4.18)$ & .03 & $2.34(1.25-4.40)$ & .01 \\
\hline Not currently married (vs married) ${ }^{b}$ & $1.34(0.58-3.07)$ & .49 & - & - \\
\hline Not tested with partner at enrollment (vs tested with partner) ${ }^{\mathrm{b}}$ & $5.95(0.65-54.3)$ & .13 & - & - \\
\hline Not tested for HIV in the 12 months before enrollment (vs tested) ${ }^{\mathrm{b}}$ & $3.12(0.91-10.68)$ & .07 & $3.38(1.04-10.95)$ & .05 \\
\hline Engaged in transactional sex (vs did not engage in transactional sex) ${ }^{d}$ & $10.33(2.48-42.95)$ & .001 & $17.64(2.88-108.14)$ & .02 \\
\hline $\begin{array}{l}\text { Had multiple sex partners in the past } 12 \text { months (vs did not have multiple } \\
\text { partners) }\end{array}$ & $3.17(0.58-17.48)$ & .19 & - & - \\
\hline \multicolumn{5}{|l|}{ Men } \\
\hline Age $40-44$ years (vs other age groups) ${ }^{b}$ & $6.90(2.75-17.34)$ & $<.001$ & $13.04(5.98-28.41)$ & $<.001$ \\
\hline Older and residing in a rural site (vs other age and residential groups) ${ }^{b}$ & $7.90(0.65-96.49)$ & .11 & - & - \\
\hline $\begin{array}{l}\text { Sought testing for HIV outside the study in the past } 12 \text { months (vs did } \\
\text { not seek testing) }\end{array}$ & $35.23(12.40-100.06)$ & $<.001$ & $8.28(1.39-49.38)$ & .02 \\
\hline $\begin{array}{l}\text { Had a sex partner residing outside the study area (vs did not have partner } \\
\text { outside study area) }\end{array}$ & $2.31(0.68-7.88)$ & .18 & - & - \\
\hline
\end{tabular}

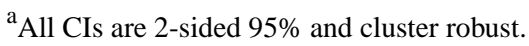

${ }^{\mathrm{b}}$ Data collected at baseline.

${ }^{\mathrm{c}}$ Variables at $P \leq .10$ in the bivariate models (Table 2) were included in the multivariable Cox models. Variables at $P>.10$ in the full model were removed for the final model. Variables at $P<.05$ in the final multivariable models were considered statistically significant.

${ }^{\mathrm{d}}$ Data collected at follow-up.

\section{Discussion}

\section{Principal Findings}

Our longitudinal, sentinel cohort study reports the first directly observed measure of HIV incidence in the adult population of Zambezi, Namibia. Nearly three decades into Namibia's epidemic, this is the first estimate of incidence for its most severely affected region. Our measure of 1.33 per $100 \mathrm{PY}$, compared with modeled HIV incidence for all Namibia during this period ( 0.78 per annum) [1], corroborates that Zambezi is a region where higher levels of HIV transmission persist. Our method, which uses an existing community-based testing program, is a replicable framework for sentinel HIV incidence surveillance that can be used in the absence of or supplemental to data obtained from other methods.

We were able to detect significant correlates of HIV seroconversion that can be used to understand the extent to which existing HIV prevention interventions are working and where additional interventions should be delivered. These include where to prioritize the deployment and scale-up of effective biomedical interventions such as enhanced test and treatment strategies and PrEP. AGYW living in rural areas had more than four times the likelihood of acquiring HIV infection compared with other women. HIV incidence among men was highest in the 40- to 44-year-old group and among older men in rural areas. These findings are consistent with a pattern of intergenerational, heterosexual transmission observed across sub-Saharan Africa $[1,8,9,25]$, which may be explained by the early sexual debut in AGYW, harmful gender norms, transactional sex, and income disparities in sexual relationships $[25,27]$. The latter two hypotheses are supported by our study's observation that transactional sex was a significant predictor of seroconversion, and by the extremely high prevalence observed among female sex workers in a separate cross-sectional study in the Zambezi region [28]. We also observed that men who sought HIV testing outside of the study between baseline and follow-up were more likely to seroconvert, suggesting men who seek frequent testing may be correctly perceiving themselves to be at elevated risk. The finding stood in contrast to women; those who did not have a history of a test before baseline were more likely to seroconvert. Women may be less likely to perceive their risk of infection (eg, their risk is from their husbands' or regular partners' behaviors), highlighting the need for home-based, provider-initiated, or other forms of testing to reach women who do not seek testing on their own. High HIV 
incidence was also observed in the Ngweze urban site. Multiple cases within this small neighborhood may suggest that we found a hotspot of transmission, highlighting the potential yield of index client partner tracing for case detection. Alternatively, the high incidence in this neighborhood may be correlated with another factor, in which case area mobile testing may diagnose additional cases. Although we observed no seroconversions among circumcised men and persons whose partners were on ART, the sample sizes were small, and we were unable to test for significance in our models. Future applications of this surveillance method would need to enroll a larger sample to assess whether the population-level prevention effects of these biomedical interventions are consistent with those observed in randomized controlled trials $[6,7,29]$. In summary, our results point to specific sexual risk and health-seeking behaviors that can be prioritized for enhanced behavioral and biomedical prevention interventions, particularly focusing on the populations and areas in the Zambezi region identified as having a higher incidence.

\section{Comparison With Prior Work}

Few recent direct measures of HIV incidence are available from longitudinal studies elsewhere in sub-Saharan Africa. HIV incidence was 2.4 per $100 \mathrm{PY}(95 \%$ CI 2.00-2.54) in a national population-based cohort in Eswatini from 2010 to 2011 [8], 0.27 per 100 PY (95\% CI 0.18-0.35) in a national population-based cohort in Rwanda from 2013 to 2014 [9], 1.11 per $100 \mathrm{PY}$ (95\% CI 0.91-1.31) in a regional population-based cohort in Gem, western Kenya from 2006 to 2016 [10], and 0.55 per $100 \mathrm{PY}(95 \%$ CI $0.45-0.66)$ in a study in rural Uganda that measured HIV incidence through home-based testing campaigns across two rounds in 2006 and 2008 [22]. The only other longitudinal measure of HIV incidence from Namibia was 2.4 per 100 PY (95\% CI 1.9-2.9) in a household-based study in Windhoek from 2007 to 2009 [23], a time when few PLHIV were on ART $[1,3]$. In an era of working to achieve HIV epidemic control worldwide, more incidence estimates from cohorts such as these are needed to assess prevention efforts and target hotspots of continuing transmission. A longitudinal sentinel incidence surveillance approach similar to ours can strike a balance of efficiency and rigor by leveraging existing HIV testing programs in high-risk areas and populations below the national level.

\section{Strengths and Limitations}

Our longitudinal sentinel incidence surveillance study points to moderately high internal validity (eg, the robustness of correlates of HIV acquisition within the sentinel population). Nearly three-fourths $(3261 / 4490,72.63 \%)$ of residents accepted home-based testing by TCE, of whom $68.02 \%$ (2218/3261) participated in our cohort. Participation was lower than that observed in the Eswatini (73.8\%) [8], western Kenya (82.6\%) [10], Rwanda (98.4\%) [9], and Windhoek cohorts (88\%) [23]. Nonetheless, our retention rate of $93.23 \%$ (1624/1742) was comparable with or higher than $41.3 \%$ in western Kenya [10], $58.0 \%$ in Windhoek [23], 64.4\% in rural Uganda [22], 91.7\% in Rwanda [9], and 94.4\% in Eswatini [8]. Moderate levels of participation and high levels of retention in our cohort led to an overall incidence estimate that was reasonably precise $(95 \% \mathrm{CI}$
0.91-1.95). However, greater precision and power to detect differences in incidence between subgroups may have been possible if more residents had participated in our cohort.

Although our results are encouraging that sentinel surveillance integrated within existing testing programs can track HIV incidence and demonstrate prevention impact, we recognize limitations. First, the sample size and few incident infections resulted in low precision for HIV incidence in subgroups, low statistical power to detect smaller effects for HIV acquisition, and an increased chance that some correlates may be because of chance. As the incidence is declining in the current era, larger sample sizes are needed to measure the impact of prevention programs. Nonetheless, the sentinel incidence surveillance approach has two advantages for increasing statistical power: purposely choosing populations with high HIV incidence and leveraging programs already testing large numbers of persons at risk. If community-based testing programs are already in place, the sentinel approach can be scaled up to include more sites with minimal additional resources, forming an integrated national system similar to antenatal clinic sentinel surveillance for HIV prevalence [30]. A second limitation is representativeness, affected by the choice of sites and by lower participation for some groups, including men, who are consistently less likely to be tested for HIV than women in settings across Africa [31]. Our incidence estimates and factor analyses among men may be biased if those who participated had different risk profiles than those who did not. Furthermore, men in our study were not asked if they had sex with other men. As such, we were not able to assess behavior among men who have sex with men (MSM) as a potential correlation of seroconversion. Other studies have shown a high prevalence among MSM in Windhoek, but the prevalence is approximately equal among MSM and the general population in less densely populated areas outside the capital [32]. Given that our study setting more closely resembles those less densely populated areas, we believe the potential biases of noninclusion or nonself-identification of MSM in our cohort to be likely low.

By design, we deliberately chose the sentinel population within the most severely affected region of Namibia and purposively selected a limited number of clusters for the sake of efficiency. Unlike the studies in Eswatini [8] and Rwanda [9], our estimates do not extrapolate to the national level. Unfortunately, data on the characteristics of clients reached by the TCE program in nonsampled areas of Zambezi were not available for analysis. Although we assume that the demographic and risk profiles of residents in sampled and nonsampled urban and rural areas across the region are comparable, we were not able to confirm this assumption and its effect on the generalizability of our results. Nonetheless, our sentinel approach produced a precise estimate for a high-priority subnational area. Moreover, the design and intention of the sentinel surveillance approach are to select sites that can provide early signals of changes in the epidemic over person, place, and time. A third limitation is that we depended upon having a large-scale, pre-existing community-based HIV testing program. The TCE program was funded to test the entire Zambezi population using a door-to-door home-based approach, presenting an opportunity to coordinate longitudinal sentinel incidence surveillance across 
a defined geographic area with minimal additional resources. The sentinel incidence surveillance approach may require the identification of other programs that conduct repeat HIV testing in defined populations or within consistent catchment areas. Fourth, participation rates in the TCE program and cohort leave room for potential bias with reduced external validity. Finally, the act of counseling and testing for HIV at baseline and the anticipation of follow-up testing may reduce risk behavior and therefore underestimate HIV incidence relative to the surrounding population.

\section{Conclusions}

We tested an efficient method to obtain a directly observed, longitudinal measure of HIV incidence in a high-prevalence region of Namibia. Nearly three decades into Namibia's epidemic, this is the first estimate of the incidence for this region. With the achievement of its target sample, high retention, and ability to detect correlates of seroconversion, our approach appears to be a viable community-based surveillance method that could be replicated in other settings serviced by similar testing programs. We believe this approach can strike a reasonable balance between the additional resources required and the ability to generate direct measures of prevention impact. As HIV testing becomes increasingly accessible and frequent, more opportunities to measure incidence through active and passive repeat testing will arise. Longitudinal sentinel incidence surveillance can be integrated into other community-based programs or facilities conducting high numbers of repeat HIV tests, such as antenatal and sexually transmitted infection clinics $[16,33,34]$, and those servicing key populations at high risk for HIV. The hard-won tools to treat and prevent HIV have placed epidemic control and elimination within reach. We need to take every opportunity to demonstrate and ensure that they are working.

\section{Acknowledgments}

For their hard work and dedication to the study, the authors thank the field officers and other staff of TCE Zambezi, including Beauty Muyoba, Beauty Mumbela, Catherine Milinga, Cecilia Mantanyani, Charity Ntema, Charity Silengano, Christopher Mayumbelo, Dorcus Mubiana, Grace Sinvula, Josephine Sombelo, Kabende Frederick, Kaela Alpha, Kwala Ednah, Matengu Musohwa, Melody Katangu, Mildred Mwilima, Nalisa Norrister, Namatama Phoustinah, Nicky Kakwena, Petronah Munzie Mubonda, Raphael Siyanga, Sarriety Bushihu, Simon M. Mukena, Progress Muzamai, Namasiku Fellyster, Moderia Mafulata, Viona Chenjekwa, and Doctrine Mukelebai. This study was funded by the President's Emergency Plan for AIDS Relief through the CDC under the terms of cooperative agreement no. U2GGH000977. The findings and conclusions in this manuscript are those of the authors and do not necessarily represent the official position of the funding agency. Internal review was required by the finding agency before authorization for submission.

\section{Conflicts of Interest}

None declared.

\section{References}

1. Joint United Nations Programme on HIV/AIDS. 2018. Country Fact sheet for Namibia URL: http://www.unaids.org/en/ regionscountries/countries/namibia [accessed 2020-03-25]

2. The Nambia Ministry of Health and Social Services. The DHS Program. 2014. The Namibia Demographic and Health Survey 2013: Final Report URL: https://dhsprogram.com/publications/publication-fr298-dhs-final-reports.cfm [accessed 2020-03-25]

3. AIDSinfo: UNAIDS. 2008 Jun. Estimates and Projections of the Impact of HIV/AIDS in Namibia URL: http://data.unaids.org/ pub/report/2008/20080915 namibia estimates 2008 en.pdf [accessed 2020-03-25]

4. UNAIDS. World Health Organization. 2016. Global AIDS Update: UNAIDS Report URL: https://www.who.int/hiv/pub/ arv/global-aids-update-2016-pub/en/ [accessed 2020-03-25]

5. The United States President's Emergency Plan for AIDS Relief. US Embassy in Namibia. 2017 Apr 28. Namibia Country Operational Plan Strategic Direction Summary, 2017 URL: https://na.usembassy.gov/wp-content/uploads/sites/132/ PEPFAR-Strategic-Direction-Summary-2017.pdf [accessed 2020-03-25]

6. Gray RH, Kigozi G, Serwadda D, Makumbi F, Watya S, Nalugoda F, et al. Male circumcision for HIV prevention in men in Rakai, Uganda: a randomised trial. Lancet 2007 Feb 24;369(9562):657-666. [doi: 10.1016/S0140-6736(07)60313-4] [Medline: 17321311]

7. Weidner W. Words of wisdom re: male circumcision for HIV prevention in young men in Kisumu, Kenya: a randomised controlled trial. Eur Urol 2007 Aug;52(2):605-606. [doi: 10.1016/j.eururo.2007.04.090] [Medline: 17674440]

8. Justman J, Reed JB, Bicego G, Donnell D, Li K, Bock N, et al. Swaziland HIV incidence measurement survey (SHIMS): a prospective national cohort study. Lancet HIV 2017 Feb;4(2):e83-e92 [FREE Full text] [doi: 10.1016/S2352-3018(16)30190-4] [Medline: 27863998]

9. Nsanzimana S, Remera E, Kanters S, Mulindabigwi A, Suthar AB, Uwizihiwe JP, et al. Household survey of HIV incidence in Rwanda: a national observational cohort study. Lancet HIV 2017 Oct;4(10):e457-e464. [doi:

10.1016/s2352-3018(17)30124-8] 
10. Borgdorff MW, Kwaro D, Obor D, Otieno G, Kamire V, Odongo F, et al. HIV incidence in western Kenya during scale-up of antiretroviral therapy and voluntary medical male circumcision: a population-based cohort analysis. Lancet HIV 2018 May;5(5):e241-e249. [doi: 10.1016/S2352-3018(18)30025-0] [Medline: 29650451]

11. Williams B, Gouws E, Wilkinson D, Karim SA. Estimating HIV incidence rates from age prevalence data in epidemic situations. Stat Med 2001 Jul 15;20(13):2003-2016. [doi: 10.1002/sim.840] [Medline: 11427956 ]

12. Downs AM, Heisterkamp SH, Ravà L, Houweling H, Jager JC, Hamers FF. Back-calculation by birth cohort, incorporating age- specific disease progression, pre-AIDS mortality and change in European AIDS case definition. European union concerted action on multinational AIDS scenarios. AIDS 2000 Sep 29;14(14):2179-2189. [doi: 10.1097/00002030-200009290-00015] [Medline: $\underline{\text { 11061660] }}$

13. Hallett TB, Zaba B, Todd J, Lopman B, Mwita W, Biraro S, ALPHA Network. Estimating incidence from prevalence in generalised HIV epidemics: methods and validation. PLoS Med 2008 Apr 8;5(4):e80 [FREE Full text] [doi:

10.1371/journal.pmed.0050080] [Medline: 18590346]

14. Guy R, Gold J, Calleja JM, Kim AA, Parekh B, Busch M, et al. Accuracy of serological assays for detection of recent infection with HIV and estimation of population incidence: a systematic review. Lancet Infect Dis 2009 Dec;9(12):747-759. [doi: 10.1016/S1473-3099(09)70300-7] [Medline: 19926035]

15. Pappaioanou M, Dondero TJ, Petersen LR, Onorato IM, Sanchez CD, Curran JW. The family of HIV seroprevalence surveys: objectives, methods, and uses of sentinel surveillance for HIV in the United States. Public Health Rep 1990;105(2):113-119 [FREE Full text] [Medline: 2157233]

16. World Health Organization. Guidelines for Conducting HIV Sentinel Serosurveys among Pregnant Women and Other Groups. Geneva: UNAIDS/WHO; 2003.

17. WHO, PEPFAR, CDC, USAID, LSTM. Planning, Implementing and Monitoring Home-Based HIV Testing and Counselling: A Practical Handbook for Sub-Saharan Africa. Geneva: World Health Organization; 2012.

18. World Health Organization. Service Delivery Approaches to HIV Testing and Counselling (HTC): A Strategic Policy Framework. Geneva: WHO; Jul 2012.

19. Bateganya M, Abdulwadud O, Kiene S. Home-based HIV voluntary counselling and testing (VCT) for improving uptake of HIV testing. Cochrane Database Syst Rev 2010 Jul 7(7):CD006493 [FREE Full text] [doi: 10.1002/14651858.CD006493.pub4] [Medline: 20614446]

20. Tabana H, Nkonki L, Hongoro C, Doherty T, Ekström AM, Naik R, et al. A cost-effectiveness analysis of a home-based HIV counselling and testing intervention versus the standard (facility based) HIV testing strategy in rural South Africa. PLoS One 2015;10(8):e0135048 [FREE Full text] [doi: 10.1371/journal.pone.0135048] [Medline: 26275059]

21. Naik R, Tabana H, Doherty T, Zembe W, Jackson D. Client characteristics and acceptability of a home-based HIV counselling and testing intervention in rural South Africa. BMC Public Health 2012 Sep 25;12:824 [FREE Full text] [doi: 10.1186/1471-2458-12-824] [Medline: 23009202]

22. Okiria AG, Okui O, Dutki M, Baryamutuma R, Nuwagaba CK, Kansiime E, et al. HIV incidence and factors associated with seroconversion in a rural community home based counseling and testing program in eastern Uganda. AIDS Behav 2014 Jan;18(Suppl 1):S60-S68. [doi: 10.1007/s10461-013-0502-4] [Medline: 23695518]

23. Aulagnier M, Janssens W, de Beer I, van Rooy G, Gaeb E, Hesp C, et al. Incidence of HIV in Windhoek, Namibia: demographic and socio-economic associations. PLoS One 2011;6(10):e25860 [FREE Full text] [doi: 10.1371/journal.pone.0025860] [Medline: 21991374]

24. Rogers WH. Regression standard errors in clustered samples. Stata Tech Bull 1994;3(13):19-23 [FREE Full text]

25. Harrison A, Colvin CJ, Kuo C, Swartz A, Lurie M. Sustained high HIV incidence in young women in southern Africa: social, behavioral, and structural factors and emerging intervention approaches. Curr HIV/AIDS Rep 2015 Jun;12(2):207-215 [FREE Full text] [doi: 10.1007/s11904-015-0261-0] [Medline: 25855338]

26. Chen X, Ender P, Mitchell M, Wells C. IDRE Stats-Statistical Consulting Web Resources. 2003. Regression with Stata: Chapter 2.4 - Checking for Multicollinearity URL: https://stats.idre.ucla.edu/stata/webbooks/reg/chapter2/ stata-webbooksregressionwith-statachapter-2-regression-diagnostics/ [accessed 2020-03-25]

27. Dellar RC, Dlamini S, Karim QA. Adolescent girls and young women: key populations for HIV epidemic control. J Int AIDS Soc 2015;18(2 Suppl 1):19408 [FREE Full text] [doi: 10.7448/IAS.18.2.19408] [Medline: 25724504]

28. UC Global Programs. 2015. Results of the 2012-2014 Integrated Biological and Behavioral Surveillance Studies among Female Sex Workers in Namibia URL: http://ucglobalprograms.org/sites/default/files/namibia-ibbss-fsw-2017.pdf [accessed 2020-03-25]

29. Cohen MS, Chen YQ, McCauley M, Gamble T, Hosseinipour MC, Kumarasamy N, HPTN 052 Study Team. Prevention of HIV-1 infection with early antiretroviral therapy. N Engl J Med 2011 Aug 11;365(6):493-505 [FREE Full text] [doi: 10.1056/NEJMoa1105243] [Medline: 21767103]

30. Ministry of Health and Social Services. 2016. Surveillance Report of the 2016 National HIV Sentinel Survey URL: http:/ /www.mhss.gov.na/documents/119527/364677/National+HIV+Sentinel+Survey+Report+2016.pdf/ 0f747cd1-84f6-4360-9586-2ce9131d3ef5 [accessed 2020-03-25]

31. Justman JE, Mugurungi O, El-Sadr WM. HIV population surveys-bringing precision to the global response. N Engl J Med 2018 May 17;378(20):1859-1861. [doi: 10.1056/NEJMp1801934] [Medline: 29768142] 
32. UC Global Programs. 2014. Results of the Namibia Men's Health Study: Integrated Biological and Behavioral Surveillance Studies among Men who have Sex with Men in Namibia URL: http://ucglobalprograms.org/sites/default/files/ namibia-ibbss-msm-2017.pdf [accessed 2020-03-25]

33. Weinstock H, Sweeney S, Satten GA, Gwinn M. HIV seroincidence and risk factors among patients repeatedly tested for HIV attending sexually transmitted disease clinics in the United States, 1991 to 1996. STD Clinic HIV seroincidence study group. J Acquir Immune Defic Syndr Hum Retrovirol 1998 Dec 15;19(5):506-512. [doi: 10.1097/00042560-199812150-00010] [Medline: 9859965]

34. Fernyak SE, Page-Shafer K, Kellogg TA, McFarland W, Katz MH. Risk behaviors and HIV incidence among repeat testers at publicly funded HIV testing sites in San Francisco. J Acquir Immune Defic Syndr 2002 Sep 1;31(1):63-70. [doi: 10.1097/00126334-200209010-00009] [Medline: 12352152]

\author{
Abbreviations \\ AGYW: adolescent girls and young women \\ aHR: adjusted hazard ratio \\ ART: antiretroviral treatment \\ CDC: Centers for Disease Control and Prevention \\ DBS: dried blood spot \\ MSM: men who have sex with men \\ PLHIV: people living with HIV \\ PrEP: pre-exposure prophylaxis \\ PY: person-years \\ TCE: Total Control of the Epidemic
}

\author{
Edited by T Sanchez; submitted 05.12.19; peer-reviewed by S Facente, K McLaughlin; comments to author 10.02.20; accepted 06.03.20; \\ published 24.06.20 \\ Please cite as: \\ Maher AD, Nakanyala T, Mutenda N, Banda KM, Prybylski D, Wolkon A, Jonas A, Sawadogo S, Ntema C, Chipadze MR, Sinvula G, \\ Tizora A, Mwandemele A, Chaturvedi S, Agovi AMA, Agolory S, Hamunime N, Lowrance DW, Mcfarland W, Patel SV \\ Rates and Correlates of HIV Incidence in Namibia's Zambezi Region From 2014 to 2016: Sentinel, Community-Based Cohort Study \\ JMIR Public Health Surveill 2020;6(2):e17107 \\ URL: http://publichealth.jmir.org/2020/2/e17107/ \\ doi: $\underline{10.2196 / 17107}$ \\ PMID: 32348290
}

(C)Andrew D Maher, Tuli Nakanyala, Nicholus Mutenda, Karen M Banda, Dimitri Prybylski, Adam Wolkon, Anna Jonas, Souleymane Sawadogo, Charity Ntema, Melody Regina Chipadze, Grace Sinvula, Annastasia Tizora, Asen Mwandemele, Shaan Chaturvedi, Afiba Manza-A Agovi, Simon Agolory, Ndapewa Hamunime, David W Lowrance, Willi Mcfarland, Sadhna V Patel. Originally published in JMIR Public Health and Surveillance (http://publichealth.jmir.org), 24.06.2020. This is an open-access article distributed under the terms of the Creative Commons Attribution License (https://creativecommons.org/licenses/by/4.0/), which permits unrestricted use, distribution, and reproduction in any medium, provided the original work, first published in JMIR Public Health and Surveillance, is properly cited. The complete bibliographic information, a link to the original publication on http://publichealth.jmir.org, as well as this copyright and license information must be included. 